\title{
Ethics in disaster management
}

\author{
Surya Parkash
}

National Institute of Disaster Management, New Delhi, India

\author{
Article history \\ Received March 2, 2012; accepted March 27, 2012. \\ Subject classification: \\ Geoethics, Earthquake disasters, Debris Flows, Landslides, Geohazards, Seismic risk, Hydrogeological risk.
}

\begin{abstract}
In any profession, a basic set of moral values needs to be followed to comply with what we call ethics. Geoscientists have significant roles to play, more particularly in the field of geohazards, to appraise society about the possibilities of natural hazards such as landslides, avalanches, floods, volcanoes, and earthquakes. Geoscientists cannot only assess these hazards, but they can also estimate the potential consequences if these hazards occur in a given place and at a given time. However, sometimes it has been found that the credibility of geoscientists among society and government is lost, due to some unethical practices for shortterm gain, or due to incorrect understanding of geological phenomena. Some of the hazards that cannot be predicted with the existing capabilities have been forecast by some pseudo-geoscientists, to draw social/media attention, thereby bringing the reputation of the profession into disrepute. There is the need to be fair enough to accept the limitations of our profession in providing information about natural hazards that are not yet fully understood by the professionals themselves. More specifically, the predictions related to earthquakes have drawn the attention of society as well as media in the developing countries where the 'common' people have different perceptions. Most often, popular myths take over scientific facts among the public, and this can lead to rumors about natural hazards. This article will mention some cases of rumors about natural disasters, and particularly earthquakes, and the response of society, media and government. It emphasizes the role of geoscientists as the ethical responsibility to inform the public about the actual situations and the geohazards, to avoid panic caused by rumors from nonspecialists or hyperactive pseudo experts. This article indicates the recent rumors about a lake outburst, flash floods, and volcanic activities after a moderate earthquake (M 6.9, September 18, 2011) in the Sikkim State of India, and considers the actions taken by the geoscientific community to correctly inform people about the real situation.
\end{abstract}

\section{Introduction}

Professional culture and ethics are very important issues for credibility, sustenance and development of any subject, particularly those related to societal, humanitarian and environmental aspects. Geosciences have contributed a lot to our understanding of the Earth and how to use it as a resource for human development. The ap- plied branches of geosciences, including for example mining geology, engineering geology, hydrogeology, environmental geology and economic geology, use geoscientific knowledge and information for the exploration and exploitation of the natural resources of the Earth, as well for the reduction and management of geo-risks. This article mainly discusses the issues related to geoscientific culture and ethics in disaster management, with some case examples from landslides, debris flows, flash floods and earthquakes in different parts of India.

\section{Case studies on earthquake disasters}

An earthquake of magnitude 6.9 struck the Sikkim State in the northeastern part of India at about 18:10 hours on September 18, 2011, with the epicentre near the IndoNepal border [Report on Sikkim Earthquake 2011]. The author had the opportunity to visit the affected area soon after the earthquake, for monitoring of the response and to carry out a quick reconnaissance of the damage/losses through a field survey. The earthquake had caused the death of about 55 people and the economic loss of approximately 200 million USD (Figure 1). During the survey, the author received information from the media and administrators in the affected area about some reports of lake outburst floods in the higher reaches of Sikkim State that were yet not accessible. The reports also indicated that some people were also suspicious about volcanic activities in the area after the earthquake. These reports created great panic among the public, as well as the State administration. The author gathered the necessary information about the geology and geomorphology of the area, and confirmed that these reports were just rumors. This professional geoscientific information helped to build confidence among the State administrations and to dispel rumors about the phenomenon. The author participated in the meetings of non-governmental organizations (Figure 2), media and government officials at the emergency operation center of the State (Figure 3), to inform all concerned about the real situation in the field based on geo- 

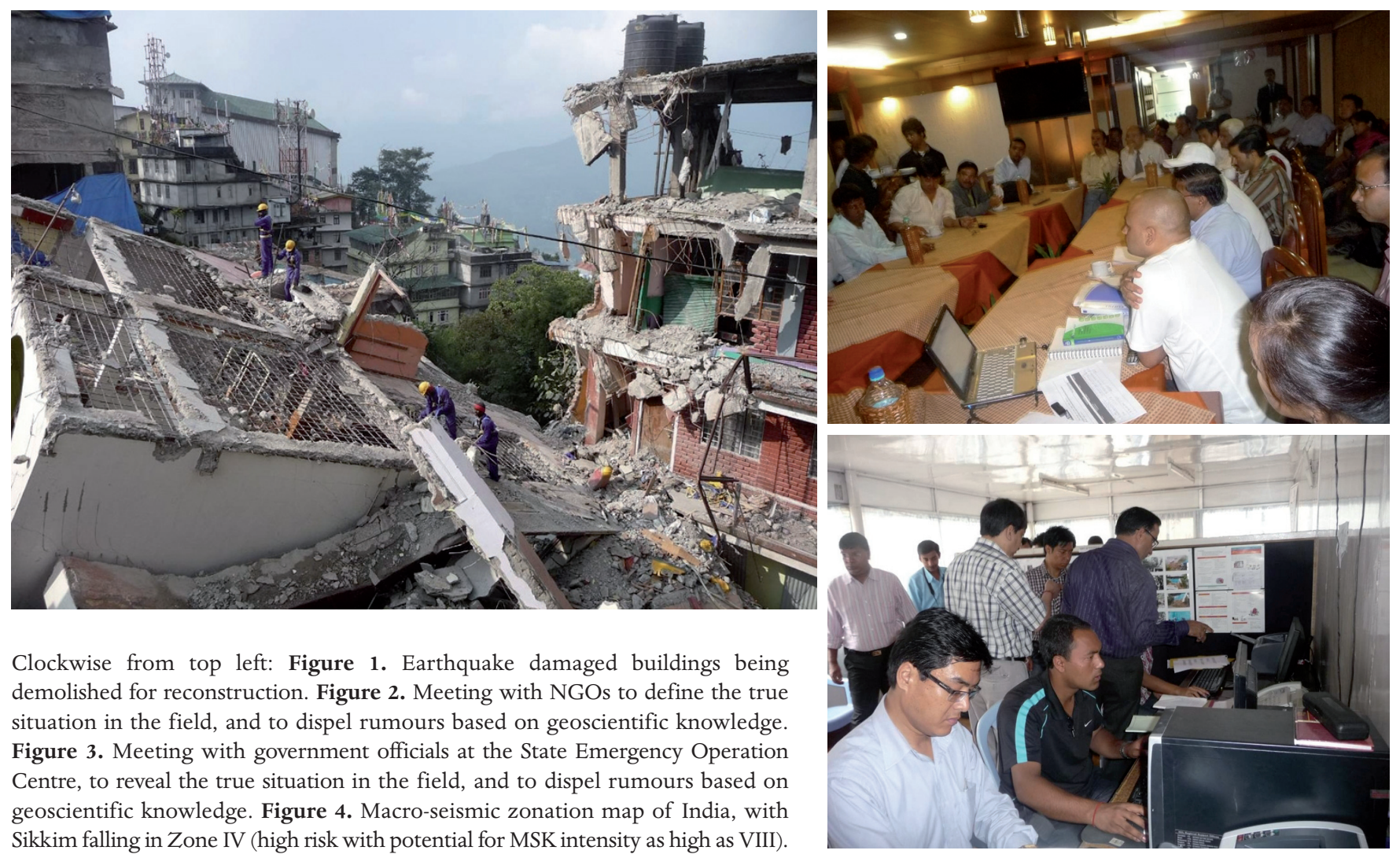

Clockwise from top left: Figure 1. Earthquake damaged buildings being demolished for reconstruction. Figure 2. Meeting with NGOs to define the true situation in the field, and to dispel rumours based on geoscientific knowledge. Figure 3. Meeting with government officials at the State Emergency Operation Centre, to reveal the true situation in the field, and to dispel rumours based on geoscientific knowledge. Figure 4. Macro-seismic zonation map of India, with Sikkim falling in Zone IV (high risk with potential for MSK intensity as high as VIII).

\section{Seismic Zone}

Map of India: -2002

\section{About 59 percent of the land area of India is liable to seismic hazard damage}

\begin{tabular}{|l|l|}
\hline Zone & Intensity \\
\hline Zone V & $\begin{array}{l}\text { Very High Risk } \\
\text { Zone Area liable } \\
\text { to shaking } \\
\text { Intensity IX (and } \\
\text { above) }\end{array}$ \\
\hline Zone IV & $\begin{array}{l}\text { High Risk Zone } \\
\text { Intensity VIII }\end{array}$ \\
\hline Zone III & $\begin{array}{l}\text { Moderate Risk } \\
\text { Zone Intensity VII }\end{array}$ \\
\hline Zone II & $\begin{array}{l}\text { Low Risk Zone } \\
\text { VI (and lower) }\end{array}$ \\
\hline
\end{tabular}

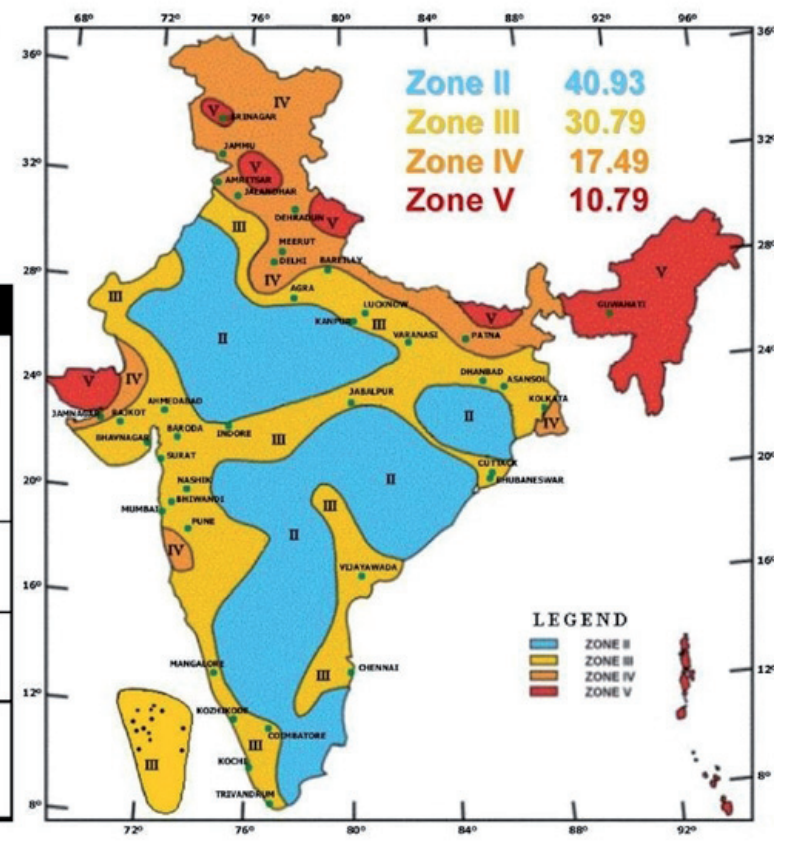

activity zone, as it formed a part of peninsular India that was considered to be relatively stable in geological terms, in comparison to other areas. The credibility of the seismic zonation map as well as the geoscientific views about spatial prediction of earthquakes was challenged by the Latur earthquake, and later led to the revision of the seismic zonation of map of India. The five seismic zones in the India map have been reduced to four seismic zones, by merging zones I and II into one category and delineating the boundaries again (Figure 4). However, the author's personal opinion related to geoscientific culture and ethics for disaster management is not very encouraging as he finds a gap in field mapping

scientific knowledge of the area. Thereafter, the response teams for post-earthquake activities planned their operations appropriately in the affected areas.

Geologists have had important roles in society by identifying earthquake prone areas through correct mapping and by assessing the possibilities of major earthquakes based on geo-tectonic and seismological studies. However, the views of geoscientists were shattered when an earthquake of magnitude $>6$ occurred at Latur in Maharashtra, India, in 1993. The area had been declared a low seismic of the related features for seismic zonation and inadequate seismic instrumentation. Therefore, to build greater confidence among society regarding geoscientific practices, we must make our claims about earthquakes on the basis of systematic field mapping and instrumental records.

However, it would be worthwhile to mention here that there have been some instances where some geoscientists have made wrong predictions about earthquakes and have communicated the same to the public through the mass media, which has resulted in panic and chaos. 
Later, these scientists even had to face the fury of the people and other members of the geoscientific community. One of these examples can be cited from Arunachal Pradesh in northeastern India, where a scientist predicted the occurrence of a major earthquake during a specific period, although nothing happened. The tribal people of the area were unhappy over such an incredible warning, and threatened the scientist not to repeat these kinds of false warnings among the public.

\section{Case studies on debris flows and landslides}

Leh town in Jammu and Kashmir State in the northwest part of India was severely affected by cloud-burstinduced debris flows in August 2010 [Ghosh and Parkash 2010]. The debris flows led to the loss of more than 140 people and an economic loss of more than 150 million USD, due to damage to buildings and infrastructure (Figure 5). The author visited the affected area soon after the disaster and interacted with the local community as well as the administration. Leh town is part of a high altitude desert area with a low rainfall (less than $100 \mathrm{~mm}$ per annum), although during August 2010, the area was suddenly hit by $200 \mathrm{~mm}$ to $250 \mathrm{~mm}$, leading to huge debris flows in the area. The area was recently afforested by efforts of the community, the local administration and environmentalists, which had changed the land scenario from barren lands to green lands. The heavy precipitation during August 2010 was considered to be due to the afforestation of the lands, which resulted in micro-climatic
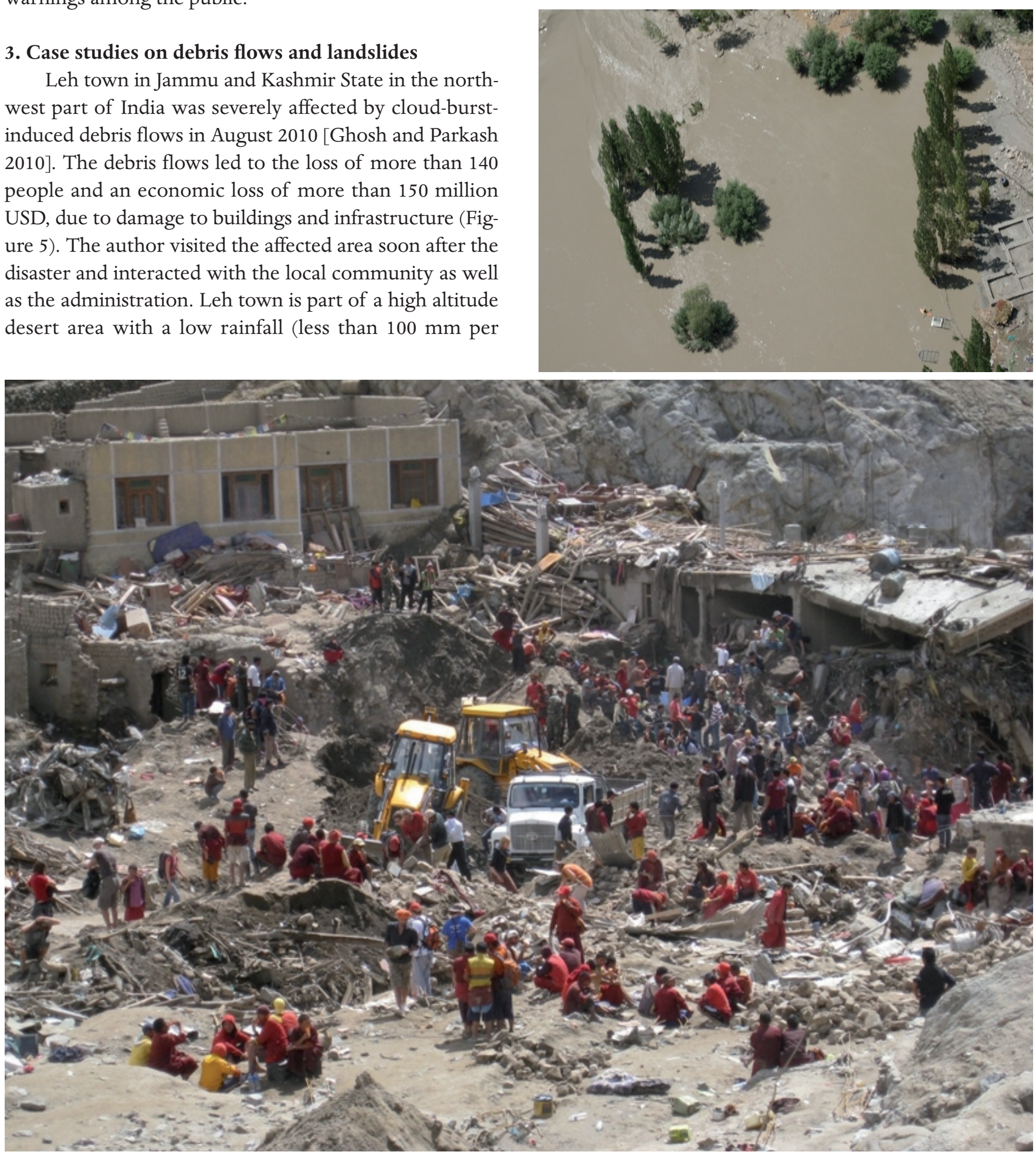

Figure 5 (top right). Flash floods and debris flow at Leh submerged and damaged buildings and infrastructure after heavy precipitation during August 2010. Figure 6 (bottom). Impact of debris flow and response of victims in Leh during the August 2010 tragedy. 

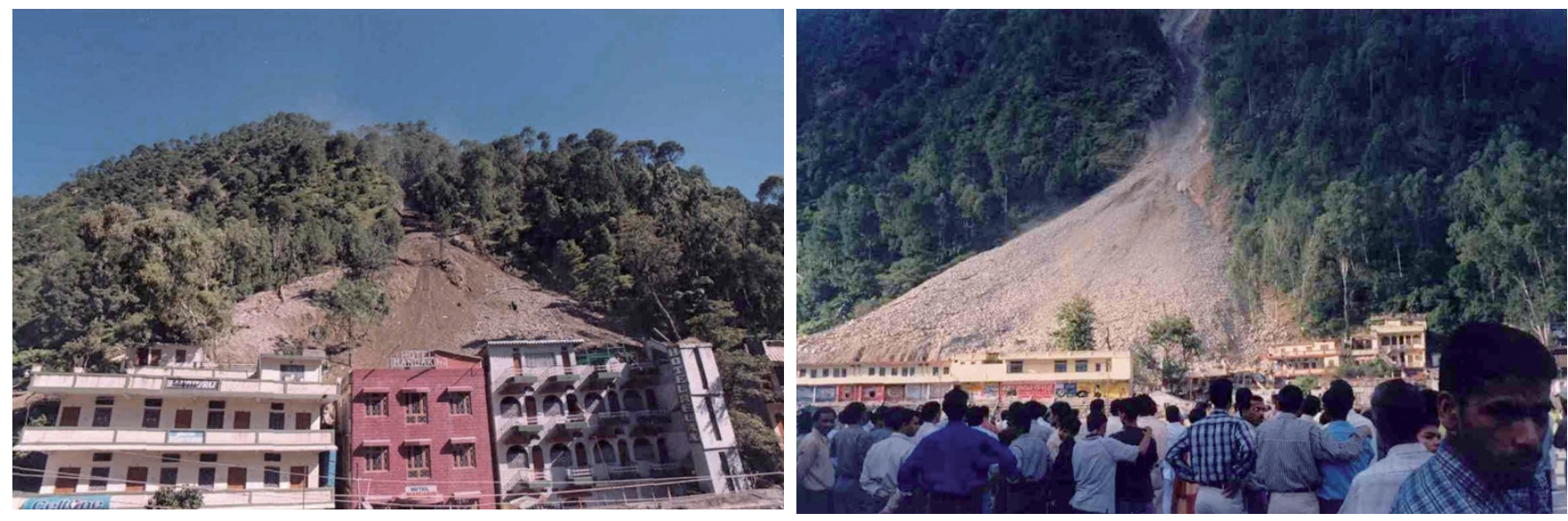

Figure 7 (left). The three four-storey hotels in the Varunawat hills in Uttarkashi Town on September 25, 2003, just the day before these buildings got buried under the landslide debris. Figure 8 (right). View of the landslide after the burial of the hotels, with people watching in panic.

changes. So, a negative opinion about the afforestation program arose among the public. The author made detailed observations in the area and found that although changes in precipitation amounts were possibly due to micro-climatic changes, the damage/losses due to rain-induced debris flows were mainly caused by the large numbers of trees planted along the banks of the rivers and of their tributaries. During the initial phase of their lives, the plants got water easily from the channels. However, during the heavy precipitation, they were uprooted and blocked the channel and the debris flow, thereby creating a temporary natural dam. These dams burst and brought huge amounts of debris on the downstream sides, causing loss of human lives and property (Figure 6). Due to the afforestation programme, the greenery of the area was a good positive step towards environmental regeneration of the area, although the plantations were not set up correctly along the banks of the rivers.

In September 2003, the author came across another landslide in the Varunawat hills in the Uttarkashi town of Uttarakhand State in northern India [Parkash 2003]. The landslide took place when a large chunk of mountain moved downhill and engulfed three four-storey hotels along the national highways, as well as damaging roads and other infrastructure (Figures 7 and 8). The author heard a rumor from local officials that the landslide was triggered by an explosion of gas inside the rock, or some volcanic activity. These myths override people's sentiments or minds, and gain ground if not properly dealt with by the geoscientific community. It was chance that the author had studied this area for landslide problems earlier and had identified this particular site as a potential landslide area based on the terrain characteristics. He informed the public and the local administration that the information about the underground gas explosion or volcanic activity was not true, as the local geology and geo-tectonic activities did not favour the occurrence of these phenomena. Rather, it was a case of a landslide and rockfall, as lots of dust had been generated following the attrition of rock materials. The dust went into the air due to the light weight and size of the small particles. Adequate information based on geoscientific data, maps and information helped the community to judge the phenomena correctly, and to take appropriate and timely initiatives. The other major issue found in ethical practices related to geohazards was the gap in communicating relevant information and reports to the authorities concerned by the geoscientists, as well as getting them to understand the phenomena. The area was surveyed by the Geological Survey of India, and a report about the possibility of landslides was given to the administration prior to its occurrence. This was why people were evacuated and lives were saved. However, it did not help the administration to understand the phenomenon well. The author used his reports of previous studies in the area, and made the factual situation at the site clear. The author was also contacted by the media, and the correct information was shared with the public through print and electronic media.

\section{Conclusions}

It can be concluded from the above case studies and discussion that the geoscientific community have a very important role to play in the field of geohazards risk management; however, it requires hard work, sincerity and honesty for ethical practices, and to maintain the credibility of this profession among the 'masses'. There might be some cases where accurate knowledge or information is not available to geoscientists due to indeterminacy or uncertainties in the nature of a geohazard, so we should then be cautious to provide our input within the given limitations.

The strength of a geoscientist lies in the correct understanding of the Earth's environment and processes, including the role of humans in causing and controlling adverse consequences of geohazardous events, like earthquakes, landslides, volcanic activity, and tsunamis. It would be good if the appropriate standards of practices in geo- 
sciences can be followed, to achieve credible and reliable results with more accurate information. The knowledge and information thus generated should be well validated through field checks and discussions among the geoscientific community, before they are shared with others.

Geoscientists should gear themselves up for a better understanding of the geohazards and for disaster-risk management. Critical assessments and evaluations should be done in the positive as well as negative roles played by geoscientists in disaster management, to improve our practices and eliminate our shortcomings.

Acknowledgements. The author would like to express thanks to the Executive Director, National Institute of Disaster Management, New Delhi, India, for his kind cooperation and support in developing this article. He would also like to thank his colleagues, the professional administrators, and people of the community who interacted with him and discussed this theme with him, which led to better understanding of the subject.

\section{References}

Ghosh, C., and S. Parkash (2010). Cloud-burst-induced debris flows on vulnerable establishments at Leh, Indian Landsl., 3, 1-6.

Parkash, S. (2003). Landslide Precursors and Potential for Monitoring Studies on Varunawat Hills at Uttarkashi, presented at the National Conference on Natural Hazards (Earthquakes $\&$ Landslides): Challenges, Perspectives and Societal Dimensions with focus on the State of Uttaranchal, Abstract p. 46.

Report on Sikkim Earthquake (2011). A Roadmap to Resurrection, submitted by the National Institute of Disaster Management, New Delhi, to the Ministry of Home Affairs, Government of India.

Corresponding author: Surya Parkash,

National Institute of Disaster Management, New Delhi, India; email: suryanidm@gmail.com.

(C) 2012 by the Istituto Nazionale di Geofisica e Vulcanologia. All rights reserved. 